\title{
Nitrogen isotope fractionation in 12 species of marine phytoplankton during growth on nitrate
}

\author{
Joseph A. Needoba ${ }^{1, *}$, N. A. Waser ${ }^{2}$, P. J. Harrison ${ }^{1,3}$, S. E. Calvert ${ }^{2}$ \\ ${ }^{1}$ Department of Botany, and ${ }^{2}$ Department of Earth and Ocean Sciences, University of British Columbia, \\ 6270 University Boulevard, Vancouver, British Columbia V6T 1Z4, Canada \\ ${ }^{3}$ Atmospheric and Marine Coastal Environmental Program, Hong Kong University of Science and Technology, \\ Clear Water Bay, Kowloon, Hong Kong SAR
}

\begin{abstract}
The nitrogen isotopic composition of 12 species of marine phytoplankton were determined by isotope ratio mass spectrometry in order to investigate isotope fractionation associated with growth on nitrate. The species, representing diatoms, coccolithophores, dinoflagellates, green algae, and cyanobacteria, were grown in batch cultures in artificial seawater under the same laboratory conditions of constant light and temperature. The species (with isotope fractionation values in parenthesis) were: Thalassiosira weissflogii $(6.2 \pm 0.4 \%)$; Chaetoceros simplex $(2.7 \pm 0.3 \%$; $)$ Ditylum brightwellii $(3.3 \pm 0.4 \%)$; Skeletonema costatum $(2.7 \pm 0.3 \%)$; Phaeodactylum tricornutum $(4.8 \pm$ $0.3 \%$ ); Emiliania huxleyi $(4.5 \pm 0.2 \%)$, Isochrysis galbana $(3.2 \pm 0.4 \%)$; Pavlova lutheri, $(3.6 \pm 0.5 \%)$; Amphidinium carterae $(2.2 \pm 0.3 \%)$; Prorocentrum minimum $(2.5 \pm 0.3 \%$ ); Dunaliella tertiolecta $(2.2 \pm 0.2 \%)$; and Synechococcus sp. $(5.4 \pm 0.6 \%$ ). There was no relationship between isotope fractionation and organism group, nor was there a direct effect of cell size or growth rate on the degree of isotope fractionation among all the groups. Overall, the results show that isotope fractionation during growth on nitrate is lower than values obtained from field samples (i.e. 4 to $9 \%$ ). These results indicate that there is no simple mechanism for describing differences in isotope fractionation between groups of phytoplankton, and that a physiological understanding of isotope fractionation during uptake and assimilation of nitrate is needed to properly understand the $\delta^{15} \mathrm{~N}$ signal generated by phytoplankton in the ocean.
\end{abstract}

KEY WORDS: Marine phytoplankton $\cdot$ Nitrogen isotope fractionation $\cdot$ Nitrate $\cdot{ }^{15} \mathrm{~N}:{ }^{14} \mathrm{~N} \cdot \mathrm{Stable}$ isotopes $\cdot$ Batch culture

Resale or republication not permitted without written consent of the publisher

\section{INTRODUCTION}

Variations in the natural abundance of the stable isotopes of nitrogen in marine and freshwater ecosystems have attracted considerable attention in recent years. The ability to detect small differences in the ${ }^{15} \mathrm{~N}:{ }^{14} \mathrm{~N}$ ratio of various pools of nitrogen, combined with knowledge of kinetic isotope fractionation during chemical and biochemical reactions, potentially provides novel ways to monitor nitrogen fluxes in the ocean on a variety of temporal and spatial scales. Thus, nitrogen isotope ratios have been applied to studies of particle and bloom dynamics in the ocean (Saino \& Hattori 1980, Altabet 1988, Minagawa et al. 2001), food web dynamics (Minagawa \& Wada 1984), paleoceanography (Altabet \& Francois 1994b), the source of new nitrogen to ecosystems (Karl et al. 1997), and pollution monitoring (McClelland \& Valiela 1998). These studies demonstrate that measuring the natural abundance of the stable isotopes of nitrogen can be a powerful and effective method for elucidating the complex processes governing the nitrogen cycle in the ocean.

To utilize the stable isotope signal in an oceanographic context requires knowledge of the chemical or biochemical sources and sinks of phytoplankton nutrients, and an understanding of isotopic fractionation during the processes involved (Goericke et al. 1994). 
Such knowledge would permit the ${ }^{15} \mathrm{~N}:{ }^{14} \mathrm{~N}$ signal of particulate organic matter (POM) to be used to estimate the extent and/or source of nitrogen that was utilized by the phytoplankton from which the POM was derived. This has been shown to be the case in several studies (Altabet 2001), although the exact relationship between the isotope signal and the POM is sometimes difficult to interpret (Minagawa et al. 2001). Knowledge of the isotope fractionation during nitrate uptake is fundamental information for studies of the isotope composition of POM. Nitrate uptake is a key process because it fuels new production and exerts a major control on the particulate flux that rains down to the seafloor (Eppley \& Peterson 1979). Isotope fractionation associated with nitrate uptake is critical in oceanic environments where nitrate utilization is incomplete in surface waters, because it leads to large increases in the $\delta^{15} \mathrm{~N}$ of POM as a result of Rayleigh fractionation (Altabet \& Francois 1994a, Wu et al. 1997). If the magnitude of isotope fractionation changes in different environmental conditions, or is variable among groups of phytoplankton, this may lead to erroneous interpretations of the $\delta^{15} \mathrm{~N}$ signal. Moreover, the isotopic composition of the source nitrogen is an important variable and can cause uncertainty when interpreting isotope fractionation, especially if more than 1 form of nitrogen is present (e.g. nitrate and ammonium), or more than one source is available (e.g. upwelling and N-fixation). These uncertainties have led to several experimental studies of $\mathrm{N}$ isotope fractionation under controlled laboratory conditions, but many questions remain unresolved. Differences in laboratory culture methods, such as stirring, aeration, and growth conditions are known to cause differences in fractionation (Wada \& Hattori 1978, Wada 1980), and variable fractionation values between different species of phytoplankton grown on the same form of nitrogen have been reported (Wada \& Hattori 1978, Montoya \& McCarthy 1995). The large range of isotope fractionation values that have been published complicates the use of isotope ratio data in applications such as ecosystem modeling and the interpretation of sediment records.

The variability in isotope fractionation reported to date may be attributable to the wide range of experimental conditions used in laboratory cultures. For this reason, we investigated nitrogen isotope fractionation by a wide range of ecologically significant phytoplankton during the uptake and assim- ilation of nitrate under the same culture conditions. Species of Bacillariophyceae, Prymnesiophyceae, Chlorophyceae, Dinophyceae, and Cyanophyceae were grown in batch culture under controlled culture conditions identical to those reported by Waser et al. (1998). The isotope fractionation values were derived from the isotopic composition of the particulate nitrogen that accumulated during exponential growth. By comparing different species and groups of phytoplankton grown under identical conditions, we were able to determine whether there are significant differences in isotope discrimination between different algal groups and between species in the same group.

\section{MATERIALS AND METHODS}

Cultures. The phytoplankton species used in this study were chosen either because of their ecological significance in the marine nitrogen cycle or because nitrogen isotope fractionation has been previously determined. The 12 species studied are listed in Table 1. All the species were obtained from the North East Pacific Culture Collection at the University of British Columbia, except for Synechococcus (Clone DC2), which was provided by Curtis Suttle at the University of British Columbia.

Each species was grown on artificial seawater (ESAW) following a modified recipe of Harrison et al. (1980) and Price et al. (1987). Nitrate was added at an initial concentration of approximately $200 \mu \mathrm{M}$. Other

Table 1. Summary of the main results and species used in this study. All cultures were obtained from the North Pacific Culture Collection (NPCC) at the University of British Columbia. Isolate DC2 was provided by Curtis Suttle at the University of British Columbia. $\varepsilon$ : enrichment factor; $\mu$ : specific growth rate

\begin{tabular}{|lcccc|}
\hline Species & Isolate & $\begin{array}{c}\varepsilon \pm \mathrm{SE} \\
(\%)\end{array}$ & $\begin{array}{c}\mu \\
\left(\mathrm{d}^{-1}\right)\end{array}$ & $\begin{array}{c}\text { Cell size } \\
\left(\mu \mathrm{m}^{3}\right)\end{array}$ \\
\hline Bacillariophyceae & & & & \\
Thalassiosira weissflogii & NPCC \#741 & $6.2 \pm 0.4$ & 0.86 & 600 \\
Chaetoceros simplex & NPCC \#591 & $2.7 \pm 0.3$ & 1.01 & 240 \\
Skeletonema costatum & NPCC \#676 & $2.7 \pm 0.3$ & 1.03 & 1200 \\
Ditylum brightwellii & NPCC \#756 & $3.3 \pm 0.4$ & 0.82 & 3000 \\
Phaeodactylum tricornutum & NPCC \#738 & $4.8 \pm 0.3$ & 1.2 & 140 \\
Prymnesiophyceae & & & & \\
Emiliania huxleyi & NPCC \#732 & $4.5 \pm 0.2$ & 0.61 & 36 \\
Isochrysis galbana & NPCC \#636 & $3.2 \pm 0.4$ & 0.47 & 37 \\
Pavlova lutheri & NPCC \#634 & $3.6 \pm 0.5$ & 0.86 & 30 \\
Dinophyceae & & & & \\
Amphidinium carterae & NPCC \#629 & $2.2 \pm 0.3$ & 0.67 & 152 \\
Prorocentrum minimum & NPCC \#720 & $2.5 \pm 0.3$ & 0.50 & 470 \\
Chlorophyceae & & & & \\
Dunaliella tertiolecta & NPCC \#1 & $2.2 \pm 0.2$ & 1.8 & 40 \\
Cyanophyceae & & & & \\
Synechococcus sp. & DC2 & $5.4 \pm 0.6$ & 1.6 & 2 \\
\hline
\end{tabular}


nutrients were added in excess of the Redfield ratio so that nitrate would be the first nutrient to be depleted at stationary phase. Carbon limitation was prevented by maintaining bicarbonate concentration at approximately $2 \mathrm{mM}$ during the exponential growth period. Standard sterile culturing techniques were used throughout all the experiments.

Each species was inoculated into 11 borosilicate flasks containing filter-sterilized culture medium. The flasks were placed in a water bath at a controlled temperature of $18^{\circ} \mathrm{C}$, and continuously illuminated with saturating light $\left(140 \mu \mathrm{mol}\right.$ photons $\left.\mathrm{m}^{-2} \mathrm{~s}^{-1}\right)$. This light level is not commonly shown to create photoinhibition in phytoplankton cells that are photoacclimated to the constant light conditions (Thompson 1991, Neale 1987). A magnetic stir bar (60 rpm) was used to suspend the cells in the medium and ensure a representative sample was obtained for each measurement. The semi-continuous cultures were acclimated to the culture conditions for at least 8 generations before being diluted to low biomass and allowed to grow for the determination of the isotope composition of the particulate nitrogen ( $\mathrm{PN})$ produced by the phytoplankton.

Biomass and nutrient analysis. Growth rates were determined by in vivo fluorescence (Turner 10-AU fluorometer) and cell counts were measured on a particle counter (Coulter Counter TA 11 or Z2). Cell volume was estimated from the Coulter Counter results assuming the cells approximated spheres. Species that could not be detected by the Coulter Counter (chain forming or very small cells) were counted with a hemocytometer, and the cell size was measured using a Zeiss inverted microscope. Samples were collected up to 4 times a day during log phase growth. Specific growth rate $(\mu)$ was calculated from the equation $N=N_{0} \mathrm{e}^{\mu t}$, where $N$ is either a measure of cell density or in vivo fluorescence and $t$ is time.

Nitrate concentrations were monitored by UV absorption (Collos et al. 1999) during the experiments in order ensure adequate sampling until stationary phase. The accuracy of the nitrate concentration measurements ranged from $4 \%$ at $200 \mu \mathrm{M}$ to $15 \%$ at $20 \mu \mathrm{M}$. Nitrate concentrations used for calculations (see next subsection) were determined by the spongy cadmium colorimetric technique (Jones 1984). This method provides precise nitrate determinations down to $0.1 \mu \mathrm{M}$.

PN and $\mathbf{N}$ isotope analysis. Samples for the determination of particulate nitrogen (PN) and $\delta^{15} \mathrm{~N}$ were collected on glass-fiber filters (GF/C or GF/F) by vacuum filtration at $0.5 \mathrm{~atm}$ to prevent cell lysis. The filters were dried in an oven at $60^{\circ} \mathrm{C}$ and preserved in a desiccator until analysis. The filtrate was analyzed for nitrate concentrations as described above. PN was measured on a Fisons automated CHN analyzer (model NA 1500, precision $\pm 1-2 \%$ ). Nitrogen isotope ratios were determined with a VG PRISM mass spectrometer connected on-line to a CHN analyzer. Dried samples were prepared by packaging each filter into a tin-foil pellet. The pellets were then combusted at $1020^{\circ} \mathrm{C}$. Results of the isotopic analyses are reported in the conventional delta notation:

$$
\delta^{15} \mathrm{~N} \% \text { o }=\left(\frac{\frac{{ }^{15} \mathrm{~N}}{{ }^{14} \mathrm{~N}} \text { sample }-\frac{{ }^{15} \mathrm{~N}}{{ }^{14} \mathrm{~N}} \text { standard }}{\frac{{ }^{15} \mathrm{~N}}{{ }^{14} \mathrm{~N}} \text { standard }}\right) \times 1000
$$

The ${ }^{15} \mathrm{~N}:{ }^{14} \mathrm{~N}_{\text {standard }}$ is atmospheric $\mathrm{N}_{2}$, which has a $\delta^{15} \mathrm{~N}$ value of $0 \%$.

Determination of isotope fractionation. We calculated the isotope fractionation factor (enrichment factor), $\varepsilon$, from the accumulated product equation of (Mariotti et al. 1981):

$$
\delta^{15} \mathrm{~N}_{\text {product }}=\delta^{15} \mathrm{~N}_{\text {substrate }, t=0}-\varepsilon \times\left(f \frac{\ln f}{(1-f)}\right)
$$

where $\delta_{\text {product }}$ is the $\delta^{15} \mathrm{~N}$ of PN, $\delta_{\text {substrate, } t=0}$ is the initial $\delta^{15} \mathrm{~N}$ of the nitrate, $\varepsilon$ is the enrichment factor, and $f$ is the fraction of nitrate remaining in the culture. This is the appropriate equation for describing isotopic fractionation that occurs in a closed culture where the product accumulates during the depletion of the substrate; a positive enrichment factor indicates discrimination against the heavy isotope.

Samples were collected throughout the range of nitrate draw-down and a linear regression of the $\delta^{15} \mathrm{~N}_{\text {product }}$ versus the value for $((f \times \ln f) /(1-f))$ (referred to hereafter as $F$ ) was calculated. A small correction was made to the $\delta^{15} \mathrm{~N}$ of PN to account for the fact that some PN was introduced by the inoculation of the cultures (Waser et al. 1999). The slope of the linear regression (see 'Results') provides a robust measure of $\varepsilon$, and the $y$-intercept is the value for $\delta_{\text {substrate }}$ at $t=0$ in the accumulated product equation. This model of isotope fractionation applies only to a 1-step unidirectional reaction. The nitrogen mass balance provides a check of the validity of the calculation. At stationary phase, the concentration of PN should equal the initial dissolved nitrate concentration of $200 \mu \mathrm{M}$. In addition, a further check of the validity of the Rayleigh distillation model is given by the $\delta^{15} \mathrm{~N}$ of the PN at stationary phase; it should equal the $\delta^{15} \mathrm{~N}$ of the source (in this case $3.8 \%$ ) when the nitrate is entirely depleted.

\section{RESULTS}

\section{Growth and mass balance}

Data on growth rates and cell volumes from all the cultures are shown in Table 1. The fastest-growing cul- 
tures were the diatoms Chaetoceros simplex and Skeletonema costatum, the chlorophyte Dunaliella tertiolecta, and the cyanobacterium Synechococcus sp., whereas the slowest-growing organisms were the prymnesiophyte Isochrysis galbana and the dinoflagellate Prorocentrum minimum. The cell volume ranged from $2 \mu^{3}$ for Synechococcus sp. to $3000 \mu^{3}$ for Ditylum brightwellii.

The growth and nitrate depletion characteristics for each species are presented in Figs. 1 \& 2. In general, the accumulation of PN corresponded to the removal of nitrate and represents the uptake and assimilation by the phytoplankton culture. The difference in time required to utilize the entire nitrate pool reflects the growth rate of the species. In all experiments nitrate was entirely depleted before the culture indicated signs of senescence, such as reduced cell division and changes in the per-cell fluorescence signal. If nitrogen is moving to another pool (such as dissolved organic nitrogen or ammonium) then it should be evident by the mass balance calculation, also shown in
Figs. 1 \& 2. Any deviation from a total mass of approximately $200 \mu \mathrm{M}$ indicates that there is missing nitrogen in the system, and this may influence the $\delta^{15} \mathrm{~N}$ of the phytoplankton (note that the initial concentration for Synechococcus sp. was $130 \mu \mathrm{M}$ ). For the diatoms (Fig. 1), the sum of the particulate nitrogen and the nitrate concentration in the medium was generally within $15 \%$ of the total nitrogen in the system. The mass balance for the remaining organisms is shown in Fig. 2. The largest loss of nitrogen from the cultures was evident in the later stages of the experiments, particularly for Emiliania huxleyi, Amphidinium carterae and Dunaliella tertiolecta. In addition to measurement errors, several factors may influence the mass balance of this 2-component system. Observations during exponential growth suggested that PN might have been underestimated because some cells attached to the wall of the borosilicate flask. However, as long as these cells continued to grow, the $\delta^{15} \mathrm{~N}$ signal of the cells in suspension in the medium and the cells attached to the wall should be identical.
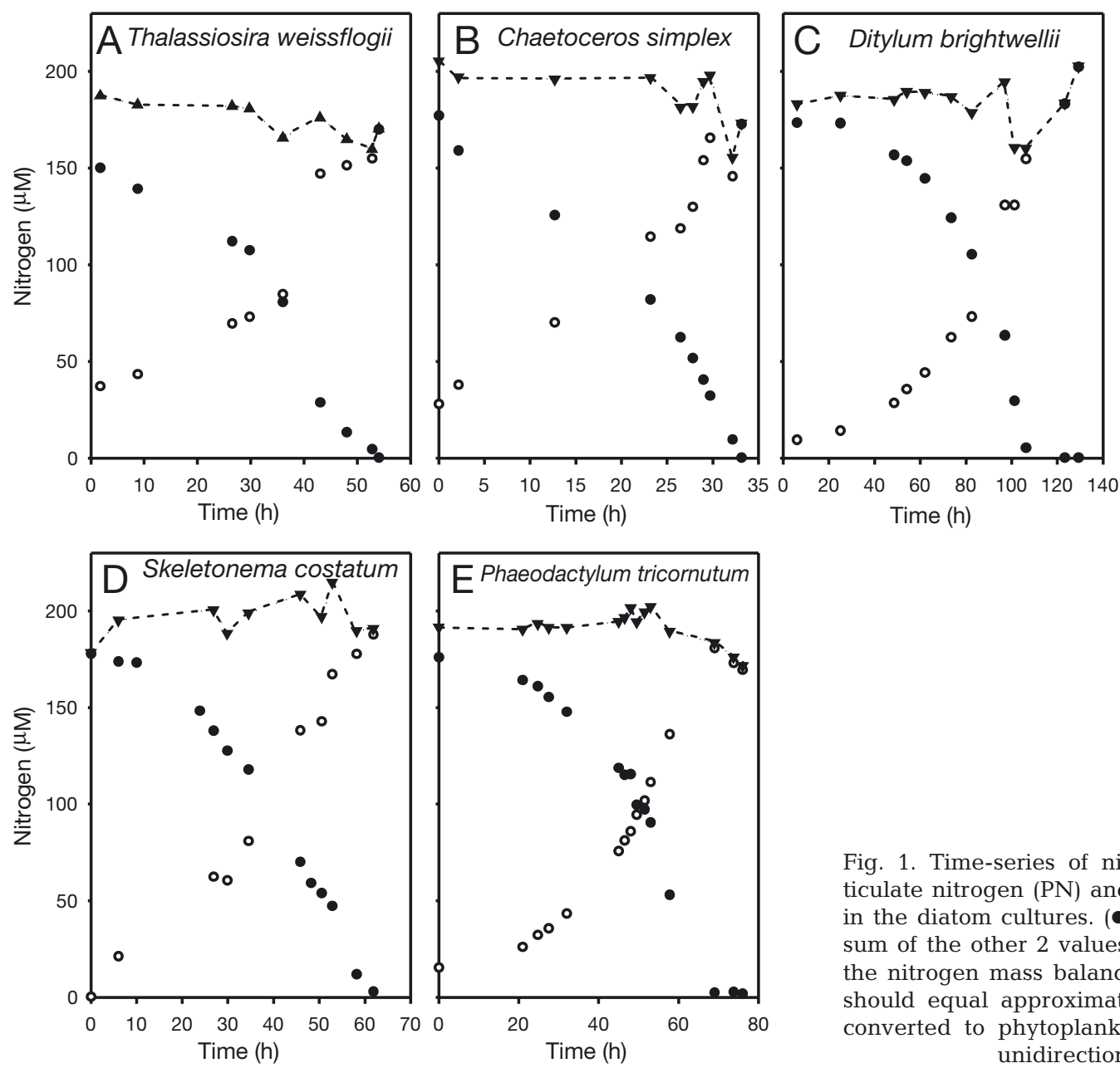

Fig. 1. Time-series of nitrate concentration, particulate nitrogen $(\mathrm{PN})$ and total $\mathrm{N}(=$ nitrate $+\mathrm{PN})$

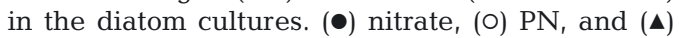
sum of the other 2 values. These figures illustrate the nitrogen mass balance in the system. Total $\mathrm{N}$ should equal approximately $200 \mu \mathrm{M}$ if nitrate is converted to phytoplankton biomass in a 1-step unidirectional reaction 

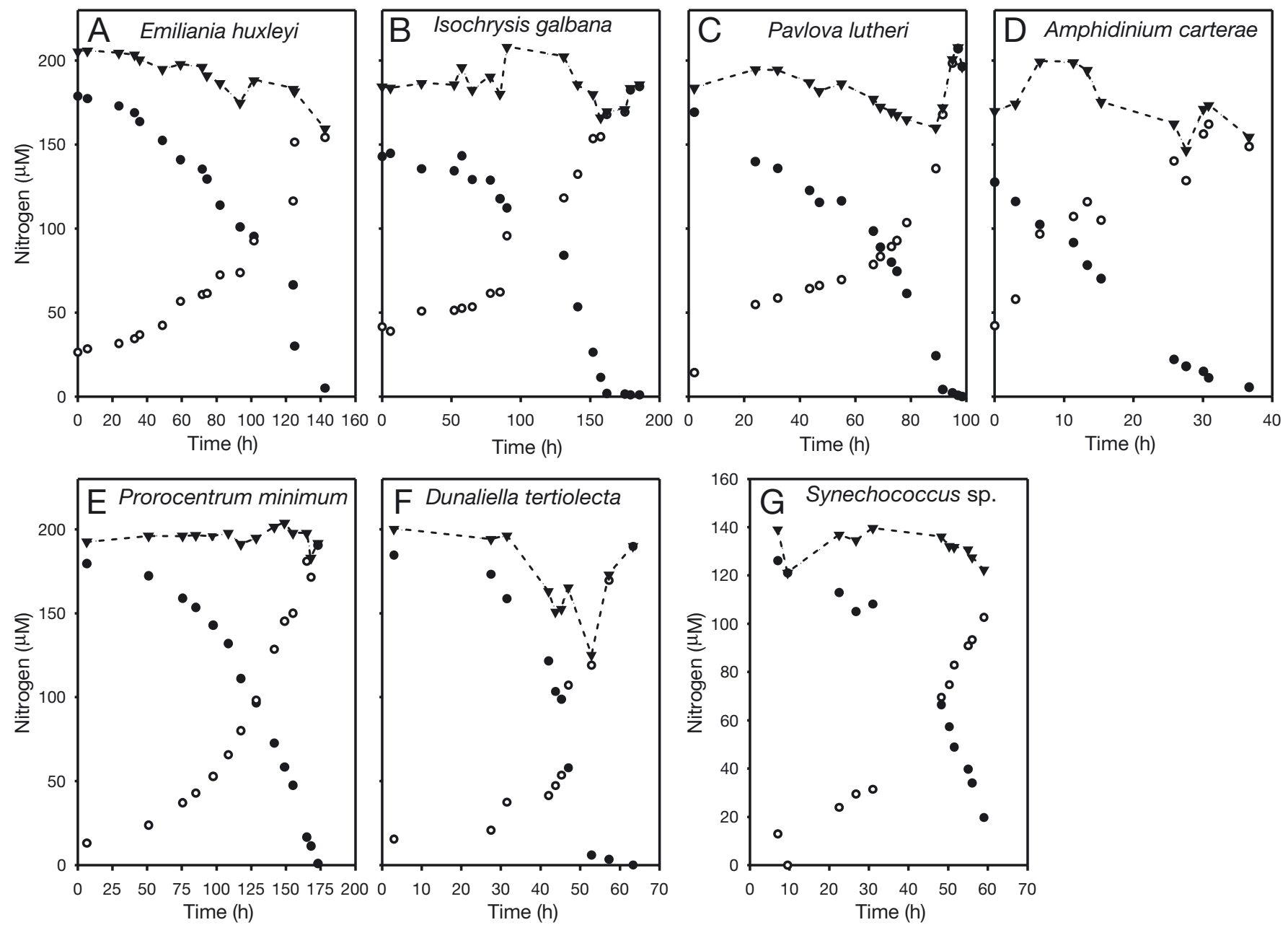

Fig. 2. Time-series of nitrate concentration, particulate nitrogen $(\mathrm{PN})$ and total $\mathrm{N}(=$ nitrate $+\mathrm{PN})$ in cultures of Prymnesiophyceae $(A-C)$, Dinophyceae $(D, E)$, Chlorophyceae (F), and Cyanophyceae (G). Symbols and explanation are as in Fig. 1

Cell stickiness will only affect the mass balance and not the determination of the epsilon value. Release of other inorganic forms of nitrogen would also affect the mass balance. However, there was no detectable nitrite produced in any of the cultures, and ammonium concentrations remained low throughout the log phase growth, and only became detectable after the cells had reached the senescence period (data not shown). The release of dissolved organic nitrogen (DON) during growth may also influence the mass balance and the isotope fractionation values. DON could be isotopically depleted (Montoya \& McCarthy 1995), therefore significant production of DON would cause the cells to be isotopically heavier than predicted by the Rayleigh model. Although DON was not measured, the $\delta^{15} \mathrm{~N}$ values for Isochrysis galbana (given below) may indicate the production of DON enriched in ${ }^{14} \mathrm{~N}$.

\section{Epsilon values}

The $\varepsilon$ values for 4 replicate cultures of Thalassiosira weissflogii are shown in Fig. 3A-D. The strong linear relationship between $\delta^{15} \mathrm{~N}$ and $F$ indicates that the process of isotope fractionation follows the Rayleigh model (see 'Materials and methods'), namely that there is 1-step unidirectional conversion of nitrate to $\mathrm{PN}$. In addition, the $y$-intercept is close to the initial $\delta^{15} \mathrm{~N}$ value of nitrate $(3.8 \%)$, indicating that all of the substrate was converted to phytoplankton biomass at the end of log phase growth. The replicate cultures yielded results that were identical within experimental error; the combined data gave $\varepsilon=6.2 \pm 0.4 \%$ for this species (Fig. 3E). Similarly, data from 4 replicates of Emiliania huxleyi can be fit with a linear regression, and the replicates yield similar results (Fig. 4). Using all data from the 4 separate experiments produces an $\varepsilon$ 

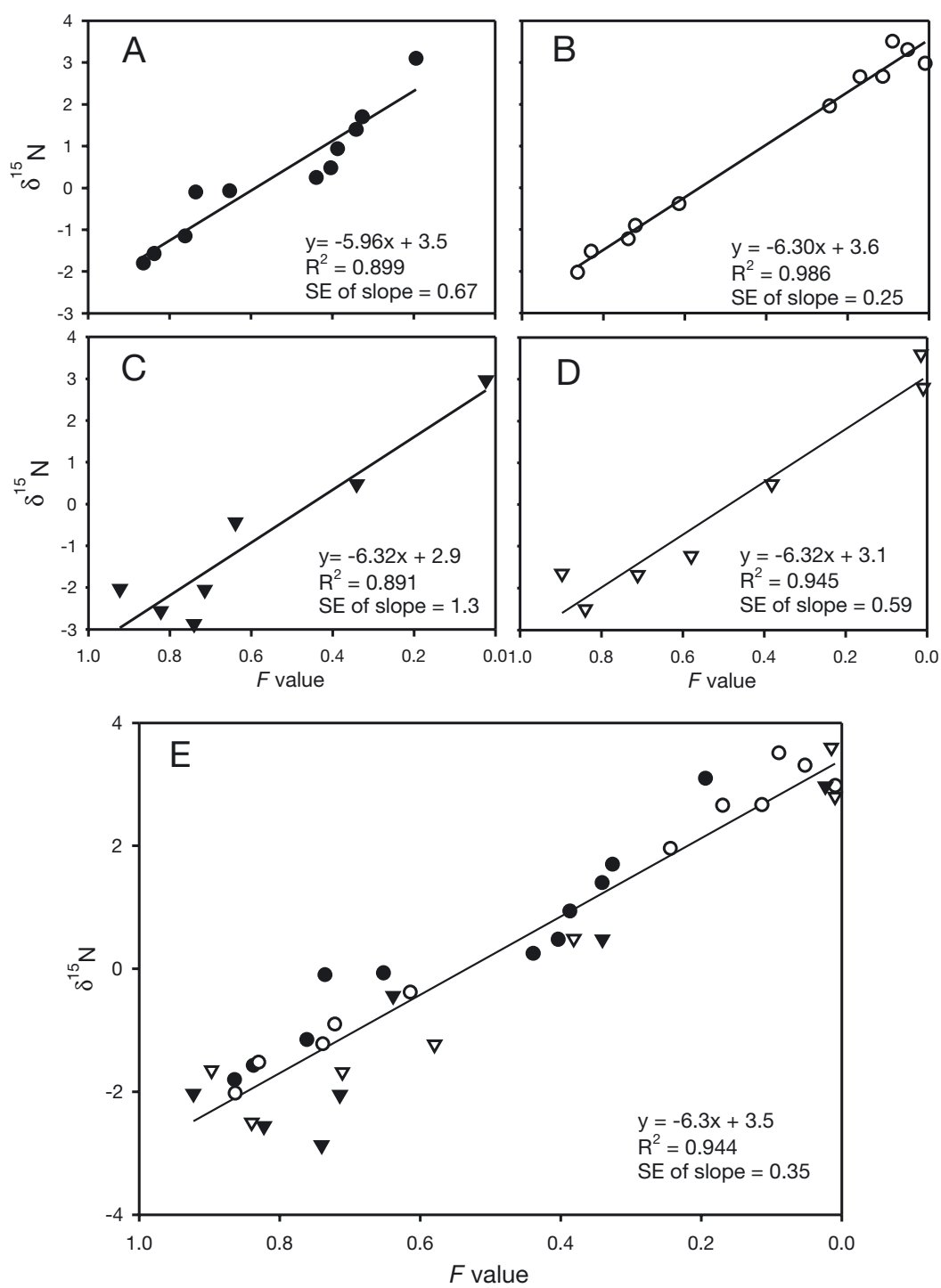

Fig. 3. Thalassiosira weissflogii. Isotope fractionation calculation. Linear regressions of the $\delta^{15} \mathrm{~N}$ of the particulate material and the $F$ value (see 'Determination of isotope fractionation' for definitions). The slope of the line represents the isotope enrichment factor, $\varepsilon$. Regressions (A) to (D) represent 4 culture vessels, and $(\mathrm{E})$ is all data combined

value of $4.5 \pm 0.2 \%$. Based on these results from 2 different groups of phytoplankton (Bacillariophyceae and Prymnesiophyceae), we have presented the results from the remaining species as a single estimate of $\varepsilon$ (Figs. $5 \& 6$ ). In some cases $\delta^{15} \mathrm{~N}$ values were determined on only 1 culture, but in these cases more than 1 culture was grown to ensure that growth rate and cell size were reproducible. In all cases, the p-value for fit of the linear regressions was $<0.01$.

Estimates of $\varepsilon$ for the other 4 diatoms used in this study are shown in Fig. 5 and listed in Table 1. While Thalassiosira weissflogii has the highest $\varepsilon(6.2 \%)$, the remaining diatoms have significantly lower values. The lowest is Skeletonema costatum $(2.7 \%$ o). This is a surprising result given that previous studies have produced much higher values for diatoms in culture (Montoya \& McCarthy 1995, Pennock et al. 1996). However, the values for the diatoms in this study are similar to the $5 \%$ fractionation factor for the diatom Thalassiosira pseudonana measured using the same culture conditions and techniques (Waser et al. 1998).

In addition to Emiliania huxleyi, 2 other prymnesiophytes yielded fractionation values of $3.2 \%$ for Isochrysis galbana, and $3.6 \%$ for Pavlova lutheri (Fig. 6A,B). In these cases, given the weaker fit of the regression lines, the change in $\delta^{15} \mathrm{~N}$ throughout the experiments suggests that isotope discrimination cannot be described by a simple 1-step model proposed above. Other processes that may account for deviations from the Rayleigh model may be the release of DON, as proposed by Montoya \& McCarthy (1995). The presence of DON was suspected in $I$. galbana, given the relatively poorer mass balance for this species (Fig. 2). E. huxleyi, Dunaliella tertiolecta, and Synechococcus sp. also show a loss of nitrogen from the 2-component system, but this effect does not appear to have influenced the isotope value obtained as indicated by the good linear fits shown in Figs. $4 \& 6$.

The dinoflagellates yielded $\varepsilon$ values of $2.2 \%$ for Amphidinium carterae and $2.5 \%$ for Prorocentrum minimum. These are the first nitrogen isotope fractionation values reported for this group of phytoplankton. The small isotope fractionation obtained is in agreement with other results that suggest that flagellated organisms have low discrimination factors (Montoya \& McCarthy 1995).

Cell stickiness is particularly evident in the chlorophyte Dunaliella tertiolecta, as the mass balance is poor, but the $\mathrm{r}^{2}$ value for the linear regression is highly significant (Fig. 4E). D. tertiolecta has an $\varepsilon$ of $2.2 \%$.

The cyanobacterium Synechococcus had an $\varepsilon$ value of $5.4 \%$, the second highest reported in this study. This species was the smallest of the organisms, and the only prokaryote in the study. The ecological significance of this group of organisms in HNLC regions (Wilhelm 1995), and the relatively high nitrogen isotope fractionation suggests that Synechococcus may be important for the $\delta^{15} \mathrm{~N}$ cycle in many regions of the ocean. 

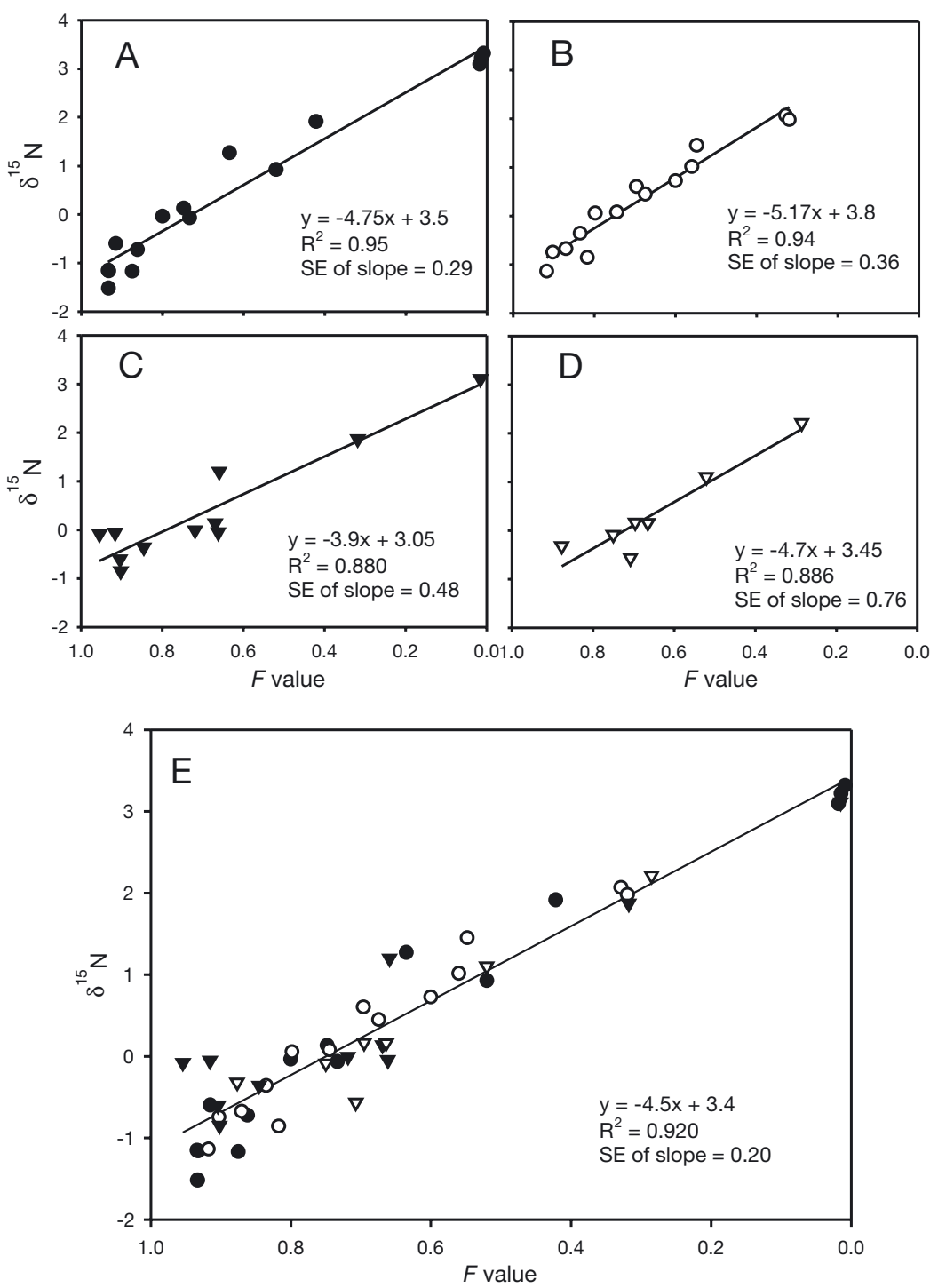

Fig. 4. Emiliania huxleyi. Isotope fractionation calculation. See Fig. 3 legend for explanation

\section{DISCUSSION}

\section{Factors affecting isotope fractionation}

In the extensive series of culture experiments reported in this paper, there do not appear to be any clear trends in the magnitude of isotope fractionation with growth rate, cell size, or species classification. As with the even more extensive work on carbon isotope fractionation by marine phytoplankton, it is apparent that the mechanism of nitrogen isotope fractionation in phytoplankton is not a function of a simple process that can be related to 1 factor, such as cell size (Rost et al. 2002). This is not surprising given the radically different life-history traits and the possible differences in the physiological mechanism of nitrate utilization exhibited by the 12 species studied. It is not clear what impact the uptake step (i.e. active transport across the plasma membrane) and the enzymatic assimilation of nitrate have on isotope fractionation measured for the whole cell. These processes can potentially influence isotope fractionation very differently, depending on the rate-limiting step for nitrate assimilation (Waser et al. 1998). The assumed high isotope fractionation associated with nitrate reductase (Schmidt \& Medina 1991) will only be expressed if the internally derived $\delta^{15} \mathrm{~N}$ signal can efflux, or leak out of the cell. While this is a common phenomenon in higher plants (Crawford \& Glass 1998), there are no direct measurements of this process for phytoplankton. It remains unclear how the interactions of uptake and assimilation of nitrate influence the biological isotope fractionation by marine phytoplankton. However, there are some important observations emerging from this study that may help to support the growing body of evidence for a physiological explanation of nitrogen isotope fractionation in phytoplankton.

\section{Swimming}

Table 2 provides a comparison of the results from this study with previous laboratory studies. Our findings support the work of Montoya \& McCarthy (1995) who showed that small, flagellated organisms have low fractionation factors when growing on nitrate. All of the species in this study that have flagella as part of their vegetative growth phase have $\varepsilon$ values lower than $3.6 \%$. It is interesting to note that the non-diatom species that lack flagella, Emiliania huxleyi and Synechococcus sp., both have relatively high $\varepsilon$ values. This suggests that the ability of a cell to swim may reduce isotope fractionation, implying that the uptake of nitrate is important in determining the magnitude of isotope fractionation. As suggested by Montoya \& McCarthy (1995), active movement of a cell from a microenvironment where nitrate is depleted below the concentration of the bulk medium may reduce the influence of a diffusive fractionating step during the process of active nitrate uptake across the plasma membrane. However, our measurements also show that the non-motile 

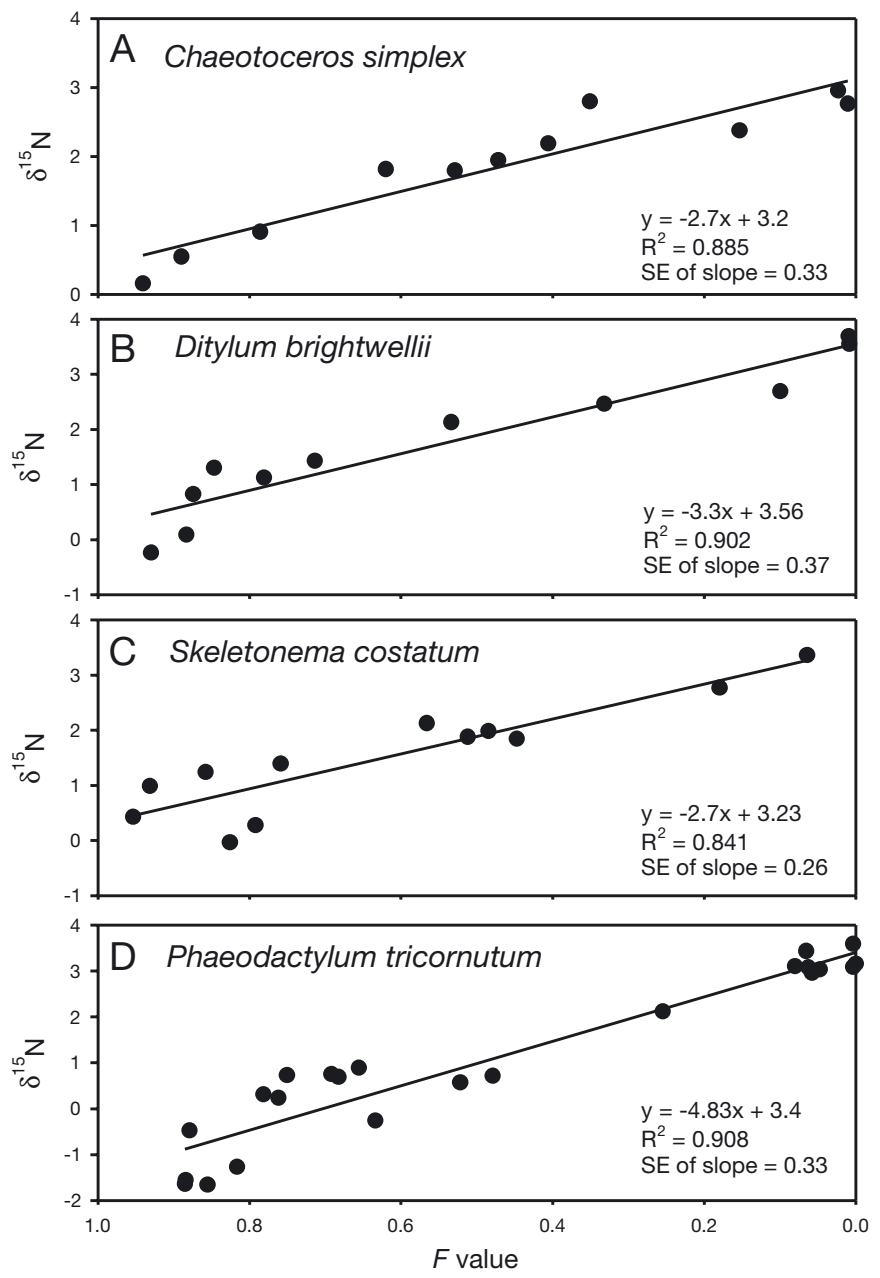

Fig. 5. Isotope fractionation calculation for the remaining Bacillariophyceae used in this study. Axis and terms as in Fig. 3

diatoms Ditylum brightwellii and Skeletonema costatum also have low fractionation factors, which illustrates the complexity of the isotope fractionation processes.

\section{Culture conditions and light}

The fractionation factors for the diatom species obtained in this study are in agreement with previous studies that use similar culture conditions. Early work on this subject (Wada \& Hattori 1978, Wada 1980) and more recent studies (Waser et al. 1998, 1999) have used batch culture methods and have demonstrated that at high growth rates, diatoms have low fractionation factors (3 to $8 \%$ ). The greatest variability, and highest fractionation, was only observed when the growth rate was lowered by reducing the available quantum flux (Wada 1980). Under these conditions, the enrichment factor was as high as $19 \%$. This suggests that light limitation alters nitrate utilization in a manner that increases isotope fractionation. We are not able to identify a specific mechanism involving light, but unpublished results from and ongoing research in our laboratory show large fractionations by Thalassiosira weissflogii under low light (J.A.N. unpubl. results).

The low $\varepsilon$ values for the diatoms are significantly different from those reported by Montoya \& McCarthy (1995) and Pennock et al. (1996), who obtained $\delta^{15} \mathrm{~N}$ values of 9 to $15 \%$ for cultures growing at their maximal growth rates. Although this discrepancy could be due to the use of different clones, a more likely explanation is the very different culture conditions used in these experiments. Montoya \& McCarthy (1995) used continuous culture conditions, whereas we used batch cultures. Riebesell et al. (2000) have found that these 2 culture designs also affect carbon isotope fractionation. Perhaps the fact that the chemostat cultures were often nitrogen-limited caused a change in the nitrate assimilation kinetics and therefore altered the isotope fractionation, compared to batch cultures where the phytoplankton are always acclimated to high nitrate concentrations. Pennock et al. (1996) grew Skeletonema costatum in batch cultures on a $12 \mathrm{~h}$ light:dark cycle, and obtained an $\varepsilon$ value of $9 \%$, whereas our cultures grew on continuous light. Cells growing on $24 \mathrm{~h}$ of continuous light may assimilate nitrate differently than on a light:dark cycle. It has been shown that diatoms continue to take up nitrate in the dark without immediately utilizing it (Stolte \& Riegman 1995). If a larger internal pool of nitrate expresses the isotope fractionation associated with nitrate reductase, estimated to be as high as $30 \%$ (Schmidt \& Medina 1991), and some of this pool escapes, then total cellular isotope fractionation could increase. During growth on continuous light, on the other hand, the nitrate is assimilated more quickly, preventing internal pools to build to levels that may cause significant leakage, thereby reducing the overall $\varepsilon$ value. Taken together with the observations that low light may influence isotope fractionation (see above), we believe that the influence of light on nitrate assimilation is an important control of isotope fractionation in phytoplankton.

High light may also influence nitrogen isotope fractionation via the processes of photoinhibition. We were not able to detect whether photoinhibition affected the growth rates of the organisms presented in this study, therefore we cannot directly address this issue with our results. In general, the light levels used in this study are lower than the light levels that often cause photoinhibition in the natural environment (Neale 1987). However, photoinhibition may alter nitrate uptake processes and could therefore be important in determining the $\delta^{15} \mathrm{~N}$ of marine phytoplankton of natural environments. 

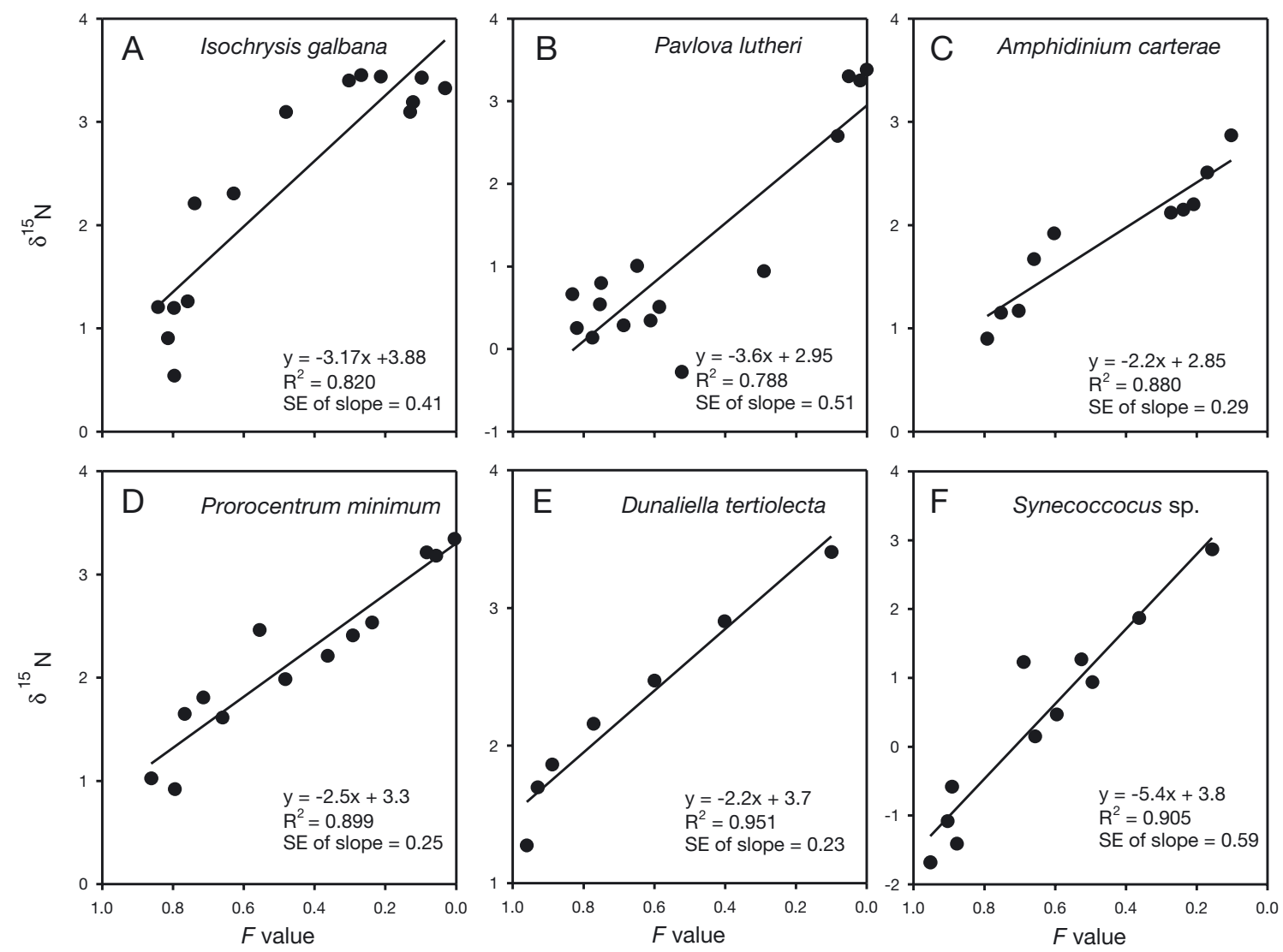

Fig. 6. Isotope fractionation calculation for the species from the groups Prymnesiophyceae (A,B), Dinophyceae (C,D), Chlorophyceae (E), and Cyanophyceae (F). Axes and terms as in Fig. 3

\section{Species effects on $\delta^{15} \mathbf{N}$}

It is difficult to extrapolate the results of this laboratory experiment to field observations due to the large differences between the artificial and the natural growth environments. However, it is interesting that the species that show larger isotope fractionations in this study are members of different groups of marine phytoplankton. The relatively high $\varepsilon$ values for Synechococcus sp. and Emiliania huxleyi suggest that natural ecosystems not dominated by diatoms can also have high isotope fractionation during nitrate utilization. Batch cultures most closely simulate a bloomforming situation, with relatively high levels of nitrate available. In these situations (e.g. spring bloom or upwelling areas), the isotope fractionation factor should have values similar to the ones presented here (i.e. 2 to $6 \%$ ). This is in agreement with recent estimates of isotope fractionation in the Southern Ocean, Subarctic Pacific, and the equatorial Pacific, which range between 4 to $6 \%$ (Altabet 2001). Each of these regions is characterized by a variety of species and groups of phytoplankton, but very similar fractionation values. Estimates of $\varepsilon$ as high as 9\% have been reported (Wu et al. 1997, Altabet 2001), and these may be examples of changing environmental conditions that stimulate a higher isotope fractionation, as has been measured by previous isotope work (see above).

Combined with previous work, the results of this study suggest that it is necessary to account for the ecological setting that will dominate the growthcontrolling processes and the species composition of the region. For example, a highly stratified water column may support a population of vertically migrating dinoflagellates that grow on nitrate acquired from below the thermocline (Koizumi et al. 1996). These communities should have low isotope fractionation factors associated with growth on nitrate, given the low fractionation values measured for flagellated phytoplankton species. In iron-limited regions, where nitrate remains high throughout the year, it is expected that isotope fractionation could be highly expressed. Competitive organisms in this environment are often small eukaryotes and cyanobacteria (Henley \& Yin 1998, Schmidt \& Hutchins 1999). The relatively large isotope fractionation that we have measured for Synechococ- 
Table 2. Comparison of $\varepsilon$ values measured in this study with previous published results. Unless otherwise noted, light conditions are similar to the light conditions used in the present study. $\varepsilon$ : enrichment factor

\begin{tabular}{|c|c|c|c|}
\hline Species & $\begin{array}{c}\varepsilon \pm \mathrm{SE} \\
(\% \circ)\end{array}$ & Culture type & Observations \\
\hline \multicolumn{4}{|l|}{ Bacillariophyceae } \\
\hline Thalassiosira weissflogii & $\begin{aligned} 6.2 & \pm 0.4^{\mathrm{a}} \\
12 & \pm 3^{\mathrm{b}}\end{aligned}$ & $\begin{array}{l}\text { Batch } \\
\text { Chemostat }\end{array}$ & Continuous light \\
\hline Thalassiosira pseudonana & $5.2 \pm 0.2^{\mathrm{c}}$ & Batch & Identical conditions as present study \\
\hline Chaetoceros simplex & $2.7 \pm 0.3^{\mathrm{a}}$ & Batch & \\
\hline Chaetoceros sp. & $0.9-4.5^{\mathrm{d}}$ & Batch & \\
\hline Skeletonema costatum & $\begin{aligned} 2.7 & \pm 0.3^{\mathrm{a}} \\
9 & \pm 2^{\mathrm{b}} \\
9 & \pm 0.2^{\mathrm{e}}\end{aligned}$ & $\begin{array}{l}\text { Batch } \\
\text { Chemostat } \\
\text { Batch }\end{array}$ & $\begin{array}{l}\text { Continuous light } \\
\text { 12:12 h light:dark cycle }\end{array}$ \\
\hline Ditylum brightwellii & $3.3 \pm 0.4^{\mathrm{a}}$ & Batch & \\
\hline Phaeodactylum tricornutum & $\begin{array}{c}4.8 \pm 0.3^{\mathrm{a}} \\
1-23^{\mathrm{d}}\end{array}$ & $\begin{array}{l}\text { Batch } \\
\text { Batch }\end{array}$ & $\begin{array}{l}\text { Large range of light intensities, culture } \\
\text { conditions }\end{array}$ \\
\hline \multicolumn{4}{|l|}{ Prymnesiophyceae } \\
\hline Emiliania huxleyi & $4.5 \pm 0.2^{\mathrm{a}}$ & Batch & No flagella or coccoliths \\
\hline Isochrysis galbana & $\begin{array}{l}3.2 \pm 0.4^{\mathrm{a}} \\
3.2 \pm 1.0^{\mathrm{b}}\end{array}$ & $\begin{array}{l}\text { Batch } \\
\text { Chemostat }\end{array}$ & \\
\hline Pavlova lutheri & $\begin{array}{l}3.6 \pm 0.5^{\mathrm{a}} \\
0.9 \pm 3.5^{\mathrm{b}}\end{array}$ & $\begin{array}{l}\text { Batch } \\
\text { Chemostat }\end{array}$ & \\
\hline Cricosphaera carterae & $7.4^{\mathrm{f}}$ & Batch & No stirring or aeration \\
\hline \multicolumn{4}{|l|}{ Dinophyceae } \\
\hline Amphidinium carterae & $2.2 \pm 0.3^{\mathrm{a}}$ & Batch & \\
\hline Prorocentrum minimum & $2.5 \pm 0.3^{\mathrm{a}}$ & Batch & \\
\hline \multicolumn{4}{|l|}{ Chlorophyceae } \\
\hline Dunaliella tertiolecta & $\begin{array}{l}2.2 \pm 0.2^{\mathrm{a}} \\
3.4 \pm 1.9^{\mathrm{b}}\end{array}$ & $\begin{array}{l}\text { Batch } \\
\text { Chemostat }\end{array}$ & \\
\hline \multicolumn{4}{|l|}{ Cryptophyceae } \\
\hline Chroomonas salina & $2.2 \pm 0.9^{\mathrm{b}}$ & Chemostat & \\
\hline \multicolumn{4}{|l|}{ Cyanophyceae } \\
\hline Synechococcus & $5.4 \pm 0.6^{\mathrm{a}}$ & Batch & \\
\hline
\end{tabular}

cus sp. could significantly affect the plankton $\delta^{15} \mathrm{~N}$ signal of such regions. Whether this signal is transferred to the bottom sediments is unclear given the low settling rates of these small organisms. When conditions allow for growth of larger phytoplankton species, such as an iron fertilization event, the $\delta^{15} \mathrm{~N}$ values of PN will be influenced by the $\delta^{15} \mathrm{~N}$ of the nitrate, which is possibly altered by the previous history of the system. Additional data on the influence of iron-limited growth on nitrate isotope fractionation will contribute to a better understanding of the $\delta^{15} \mathrm{~N}$ signal in HNLC regions.

In summary, nitrogen isotope fractionation factors for the groups of marine phytoplankton presented here are somewhat variable, but this variability does not appear to be as large as previously observed. Part of the reason for this may be that we used continuous light in our culture experiments, and this may reduce the expression of isotope fractionation by processes within the cell. The low values of $\varepsilon$ for the diatom species may be reconciled with previous studies by determining the influence of light on nitrate uptake and isotope fractionation. In addition, further studies of the influence of the release of DON on $\varepsilon$ values, and the isotope fractionation associated with cells whose nutritional status is not optimal (i.e. not in batch culture conditions), are required to properly understand the $\delta^{15} \mathrm{~N}$ signal generated by phytoplankton in the ocean. However, our results are consistent with other studies using similar culture techniques, and indicate that isotope fractionation is variable both within groups and between groups of marine phytoplankton. This implies that knowledge of the type of ecosystem and the species present is important when interpreting $\delta^{15} \mathrm{~N}$ signals in oceanic environments. 
Acknowledgements. Funding for this research was provided by the Natural Sciences and Engineering Research Council (NSERC) of Canada. We thank B. Nielsen for carrying out the isotope ratio determinations.

\section{LITERATURE CITED}

Altabet M (1988) Variations in nitrogen isotopic composition between sinking and suspended particles: implications for nitrogen cycling and particle transformation in the open ocean. Deep-Sea Res 35:535-554

Altabet MA (2001) Nitrogen isotopic evidence for micronutrient control of fractional $\mathrm{NO}_{3}{ }^{-}$utilization in the equatorial Pacific. Limnol Oceanogr 46:368-380

Altabet M, Francois R (1994a) The use of nitrogen isotopic ratio for reconstruction of past changes in surface ocean nutrient utilization. In: Zahn R, Pedersen TF, Kaminski M, Labeyrie LD (eds) Carbon cycling in the glacial ocean: constraints on the ocean's role in global change, Vol I17. Springer-Verlag, Berlin, p 281-305

Altabet MA, Francois R (1994b) Sedimentary nitrogen isotopic ratio as a recorder for surface ocean nitrate utilization. Global Biogeochem Cycles 8:103-116

Collos Y, Mornet F, Sciandra A, Waser N, Larson A, Harrison PJ (1999) An optical method for the rapid measurement of micromolar concentrations of nitrate in marine phytoplankton cultures. J Appl Phycol 11:179-184

Crawford NM, Glass ADM (1998) Molecular and physiological aspects of nitrate uptake in plants. Trends Plant Sci 3: 389-395

Eppley RW, Peterson BJ (1979) Particulate organic matter flux and planktonic new production in the deep ocean. Nature 282:677-680

Goericke R, Montoya JP, Fry B (1994) Physiology of isotopic fractionation in algae and cyanobacteria. In: Lajtha $\mathrm{K}$, Michener RH (eds) Stable isotopes in ecology and environmental science. Blackwell Scientific Publications, Oxford, p 187-221

Harrison PJ, Waters RE, Taylor FJR (1980) A broad spectrum artificial seawater medium for coastal and open ocean phytoplankton. J Phycol 16:28-35

Henley WJ, Yin Y (1998) Growth and photosynthesis of marine Synechococcus (Cyanophyceae) under iron stress. J Phycol 34:94-103

Jones MN (1984) Nitrate reduction by shaking with cadmium: alternative to cadmium columns. Water Res 18:643-646

Karl DM, Letelier R, Tupas L, Dore J, Christian J, Hebel D (1997) The role of nitrogen fixation in biogeochemical cycling in the subtropical North Pacific Ocean. Nature 388:533-538

Koizumi Y, Uchida T, Honjo T (1996) Diurnal vertical migrations of Gymnodinium mikimotoi during a red tide in Hoketsu Bay, Japan. J Plankton Res 18:289-294

Mariotti A, Germon JC, Hubert P, Kaiser P, Letolle R, Tardieux A, Tardieux P (1981) Experimental determination of nitrogen kinetic isotope fractionation: some principles; illustration for the denitrification and nitrification processes. Plant Soil 62:413-430

McClelland J, Valiela WI (1998) Linking nitrogen in estuarine producers to land-derived sources. Limnol Oceanogr 43: $577-585$

Minagawa M, Wada E (1984) Stepwise enrichment of ${ }^{15} \mathrm{~N}$ along food chains: further evidence and the relation between ${ }^{15} \mathrm{~N}$ and animal age. Geochem Cosmochim Acta 48: $1135-1140$
Minagawa M, Ohashi M, Kuramoto T, Noda N (2001) $\delta^{15} \mathrm{~N}$ of PON and nitrate as a clue to the origin and transformation of nitrogen in the Subarctic North Pacific and its marginal sea. J Oceanogr 57:285-300

Montoya JP, McCarthy JJ (1995) Isotopic fractionation during nitrate uptake by phytoplankton grown in continuousculture. J Plankton Res 17:439-464

Neale PJ (1987) Algal photoinhibition and photosynthesis in the aquatic envrionment. In: Kyle DJ, Osmond CB, Arntzen CJ (eds) Photoinhibition, Topics in Photosynthesis, Vol 9. Elsevier, Amsterdam, p 36-66

Pennock JR, Velinski DJ, Ludham DJ, Sharp JH, Fogel ML (1996) Isotope fractionation of ammonium and nitrate during the uptake by Skeletonema costatum: implications for the $\delta^{15} \mathrm{~N}$ dynamics under bloom conditions. Limnol Oceanogr 41:451-459

Price NM, Thompson PA, Harrison PJ (1987) Selenium: an essential element for growth of the coastal marine diatom Thalassiosira pseudonana (Bacillariophyceae). J Phycol 23:1-9

Riebesell U, Revill AT, Holdsworth DG, Volkman JK (2000) The effects of varying $\mathrm{CO}_{2}$ concentration on lipid composition and carbon isotope fractionation in Emiliania huxleyi. Geochem Cosmochim Acta 64:4179-4192

Rost B, Zondervan I, Riebesell U (2002) Light-dependent carbon isotope fractionation in the coccolithophorid Emiliania huxleyi. Limnol Oceanogr 47:120-128

Saino T, Hattori A (1980) ${ }^{15} \mathrm{~N}$ natural abundance of suspended organic matter. Nature 283:752-754

Schmidt HL, Medina R (1991) Possibilities and scope of the double isotope effect method in the elucidation of mechanisms of enzyme catalyzed reactions. Isotopenpraxis $27: 1-4$

Schmidt MA, Hutchins DA (1999) Size-fractionated biological iron and carbon uptake along a coastal to offshore transect in the NE Pacific. Deep-Sea Res II 46:2487-2503

Stolte W, Riegman R (1995) Effect of phytoplankton cell size on transient state nitrate and ammonium uptake kinetics. Microbiology 141:1221-1229

Thompson PA, Harrison PJ, Parslow JS (1991) Influence of irradiance on cell-volume and carbon quota for 10 species of marine phytoplankton. J Phycol 27:351-360

Wada E (1980) Nitrogen isotope fractionation and its significance in biogeochemical processes occurring in marine environments. In: Goldberg ED, Horibe Y, Saruhashi K (eds) Isotope marine chemistry. Uchida-Rokakuho, Tokyo, p 375-398

Wada E, Hattori H (1978) Nitrogen isotope effects in the assimilation of inorganic nitrogenous compounds by marine diatoms. Geomicrobiol J 1:85-101

Waser NAD, Harrison PJ, Nielsen B, Calvert SE, Turpin DH (1998) Nitrogen isotope fractionation during the uptake and assimilation of nitrate, nitrite, ammonium, and urea by a marine diatom. Limnol Oceanogr 43:215-224

Waser NAD, Yu ZM, Yin KD, Nielsen B, Harrison PJ, Turpin DH, Calvert SE (1999) Nitrogen isotopic fractionation during a simulated diatom spring bloom: importance of $\mathrm{N}$-starvation in controlling fractionation. Mar Ecol Prog Ser 179:291-296

Wilhelm SW (1995) Ecology of iron-limited cyanobacteria: a review of physiological responses and implications for aquatic systems. Aquat Microb Ecol 9:295-303

Wu JP, Calvert SE, Wong CS (1997) Nitrogen isotope variations in the subarctic northeast Pacific: relationships to nitrate utilization and trophic structure. Deep-Sea Res I $44: 287-314$

Submitted: October 9, 2002; Accepted: April 3, 2003

Proofs received from author(s): June 12, 2003 